\title{
A convex programming framework for optimal and bounded suboptimal well field management
}

Dorini, Gianluca Fabio ; Thordarson, Fannar Ørn; Bauer-Gottwein, Peter; Madsen, H.; Rosbjerg, Dan; Madsen, Henrik

Published in:

Water Resources Research

Link to article, DOI:

10.1029/2011WR010987

Publication date:

2012

Document Version

Publisher's PDF, also known as Version of record

Link back to DTU Orbit

Citation (APA):

Dorini, G. F., Thordarson, F. Ø., Bauer-Gottwein, P., Madsen, H., Rosbjerg, D., \& Madsen, H. (2012). A convex programming framework for optimal and bounded suboptimal well field management. Water Resources Research, 48, W06525. https://doi.org/10.1029/2011WR010987

\section{General rights}

Copyright and moral rights for the publications made accessible in the public portal are retained by the authors and/or other copyright owners and it is a condition of accessing publications that users recognise and abide by the legal requirements associated with these rights.

- Users may download and print one copy of any publication from the public portal for the purpose of private study or research.

- You may not further distribute the material or use it for any profit-making activity or commercial gain

- You may freely distribute the URL identifying the publication in the public portal 


\title{
A convex programming framework for optimal and bounded suboptimal well field management
}

\author{
G. F. Dorini, ${ }^{1}$ F. Ö. Thordarson, ${ }^{1}$ P. Bauer-Gottwein, ${ }^{2}$ H. Madsen, ${ }^{3}$ D. Rosbjerg, ${ }^{2}$ \\ and H. Madsen ${ }^{1}$ \\ Received 1 June 2011; revised 1 May 2012; accepted 9 May 2012; published 20 June 2012.
}

[1] This paper presents a groundwater management model, considering the interaction between a confined aquifer and an unlooped Water Distribution Network (WDN), conveying the groundwater into the Water Works distribution mains. The pumps are controlled by regulating the characteristic curves. The objective of the management is to minimize the total cost of pump operations over a multistep time horizon, while fulfilling a set of time-varying management constraints. Optimization in groundwater management and pressurized WDNs have been widely investigated in the literature. Problem formulations are often convex, hence global optimality can be attained by a wealth of algorithms. Among these, the Interior Point methods are extensively employed for practical applications, as they are capable of efficiently solving large-scale problems. Despite this, management models explicitly embedding both systems without simplifications are rare, and they usually involve heuristic techniques. The main limitation with heuristics is that neither optimality nor suboptimality bounds can be guarantee. This paper extends the proof of convexity to mixed management models, enabling the use of Interior Point techniques to compute globally optimal management solutions. If convexity is not achieved, it is shown how suboptimal solutions can be computed, and how to bind their deviation from the optimality. Experimental results obtained by testing the methodology in a well field located nearby Copenhagen (DK), show that management solutions can consistently perform within the $99.9 \%$ of the true optimum. Furthermore it is shown how not considering the Water Distribution Network in optimization is likely to result in unfeasible management solutions.

Citation: Dorini, G. F., F. Ö. Thordarson, P. Bauer-Gottwein, H. Madsen, D. Rosbjerg, and H. Madsen (2012), A convex programming framework for optimal and bounded suboptimal well field management, Water Resour. Res., 48, W06525, doi:10.1029/2011WR010987.

\section{Introduction}

[2] This paper deals with optimization in water resources management. The steadily increasing overexploitation and inefficient management of the water resources have led to a number of water quality and related health problems worldwide. Optimization in both design and operation is widely recognized as a key element in water resources planning and management. In this paper, a groundwater management problem is considered, where the water is drawn from a well field and conveyed to the Water Works distribution mains through a Water Distribution Network (WDN). The objective is to minimize the cost of pump operations, while fulfilling several management constraints. There are two

${ }^{1}$ DTU Informatics, Technical University of Denmark, Kongens Lyngby, Denmark.

${ }^{2}$ DTU Environment, Technical University of Denmark, Kongens Lyngby, Denmark.

${ }^{3}$ DHI Water-Environment-Health, Danish Hydraulic Institute, Hørsholm, Denmark.

Corresponding author: G. F. Dorini, DTU Informatics, Technical University of Denmark, Richard Petersens Plads, Bldg. 305, DK-2800 Kongens Lyngby, Denmark. (gido@imm.dtu.dk)

(C)2012. American Geophysical Union. All Rights Reserved. 0043-1397/12/2011WR010987 main branches in the literature lying within the scope of this paper. One looks at groundwater management models; the other investigates operational efficiency in WDNs.

[3] Groundwater management models are optimization frameworks where simulation of groundwater systems are employed. Stresses and the state of the aquifer are in those problems formalized as objective functions and constraints. Groundwater management models can be classified as solving problems involving groundwater flow only or solving problems involving both flow and transport of contaminants [Ahlfeld and Baro-Montes, 2008]. The interested reader may find comprehensive reviews of the literature related to the simulation-optimization approach in the following publications: Gorelick [1983]; Yeh [1992]; Ahlfeld and Heidari [1994]; Mays and Tung [1992]; Mays [1997]. Since the first combination of numerical simulation models with optimization for groundwater applications [Maddock, 1972], the range of optimization applications of groundwater problems has grown substantially [Wagner, 1995; Ahlfeld and Mulligan, 2000]. Many types of optimization problems have been studied in groundwater resources management, including pumping cost minimization [Sidiropoulos and Tolikas, 2004], water quality optimization, seawater intrusion and nitrate pollution, [Katsifarakis et al., 1999; Park and Aral, 2004; Katsifarakis and Petala, 2006; Minciardi et al., 2007]. In many cases, pumping cost is a 
fundamental element in aquifer restoration problems, [Shieh and Peralta, 2005; Matott et al., 2006; Papadopoulou et al., 2007]. Over the years, and also due to the improvement in the capability of commercial computers, researchers have experimented with the application of a wide range of optimization techniques to groundwater management models, such as linear and nonlinear programming [Bear, 1979; Rastogi, 1989; Theodossiou, 2004]; genetic algorithms and other evolutionary techniques e.g., [Ouazar and Cheng, 2000; Mantoglou et al., 2004; Kalwij and Peralta, 2008; He et al., 2008]; the outer approximation method [Spiliotopoulos et al., 2004]. A comparative study of different optimization methods applied to groundwater management problems is presented in papers by Mayer et al. [2002] and Fowler et al. [2008].

[4] In the field of operational efficiency in WDNs, pumping energy costs has always been acknowledged as a fundamental part of the operational cost of water distribution systems worldwide. Even a small overall increase in operational efficiency would result in significant cost savings to industry and municipalities [van Zyl et al., 2004]. Pump operation inefficiencies may be caused by inefficient pumps, inefficient pump combinations, and inefficient pump scheduling [Ormsbee et al., 1989]. Various optimization techniques have been applied to the operational optimization problem, including linear programming [Jowitt and Germanopoulos, 1992; Burnell et al., 1993]; nonlinear programming [Chase and Ormsbee, 1993; Yu et al., 1994]; dynamic programming [Lansey and Awumah, 1994; Nitivattananon et al., 1996]; fuzzy logic [Angel et al., 1999]; nonlinear heuristic optimization [Ormsbee and Reddy, 1995; Kansal et al., 2001]; flexible constraint satisfaction [Likeman, 1993]; and genetic algorithms (see e.g., van Zyl et al. [2004]).

[5] Even though optimization in groundwater management and pressurized WDNs have been extensively investigated, management models that are explicitly based on their dynamic interaction are still limited. In fact, in WDN optimization, aquifers are normally treated as underground reservoirs of given groundwater heads, whereas pressurized water hydraulics in the pipeline connecting well pumps is either neglected or simplified in groundwater management problems [McKinney and Lin, 1994, 1995]. Optimization of mixed management models is usually solved using heuristics. Tsai et al. [2009] employed Genetic Algorithms to solve a management model of a large-scale pressurized water distribution system and a three-dimensional groundwater model. It is important to note that heuristics do not guarantee global guarantee optimality.

[6] Nonheuristic optimization techniques are normally supported by proofs of optimality, however their applicability is subject to restrictive conditions. In groundwater flow management, problem formulations often involve linear or at most convex objective functions and convex constraints; a comprehensive illustration of this can be found in the work of Ahlfeld and Mulligan [2000]. For this class of problems, called "convex optimization problems," optimality can be achieved by a wealth of algorithms. Among these, the Interior Point methods (IP) are extensively employed for practical applications, as they are often capable of solving problems within a number of operations not more than polynomial of the problem dimensions. An extensive review of convex programming and IP methods can be found in books by Ben-Tal and Nemirovski [2001], and by Boyd and Vandenberghe [2004].

[7] A management model that does not take the WDN into account yields a time series of pumping stresses that are optimal only under the assumption that nodes heads are fixed. The more the head loss due to the friction across the WDN, the more the solution is likely to be suboptimal. More importantly, the solution may not be even feasible in the real system, as the management constraints could be violated. For some systems, this can be overcome using approximations of the WDN. The most common way is to consider the additional head loss at each individual well node, as quadratic function of the pumping stress (see e.g., Ahlfeld and Mulligan [2000]). However, with more pumping wells connected to the WDN, further complexity is added, and considering the actual system over approximations is preferable. In this paper we discuss the convexity of optimal management problems, for systems of confined aquifers and unlooped WDNs. We show that for those problems, interior points are always applicable, therefore large-scale problems can be efficiently solved considering the contribution of the WDN. The contents of this paper is organized as follows. Section 2 introduces some relevant concept of convex optimization. Section 3 describes the problem of performing discrete-time simulations of an aquifer-WDN system. The management problem is defined in section 4 . The conditions under which such a problem is convex, allowing for the use of IP methods, are identified and proved. One important condition is that pumps characteristics must be a concave functions of the head difference. The validity of this condition is discussed in section 5 . When it is not valid, it is shown how IP methods can still be used to yield quasi-optimal solutions, and bounds on their deviation from the optimal solution. Section 6 describes the implementation of the methodology in a well field simulation modeling software package. An example of real life application is discussed in section 7. Conclusions and future remarks are in section 8. Proofs of the convexity of the management problem are provided in Appendix A.

\section{Notation and Convex Optimization}

[8] In what follows, bold letters $\mathbf{x}, \mathbf{y}$ are column vectors, and ${ }^{\top}$ denotes transposition. Let function $c: \mathfrak{R}^{n} \rightarrow \mathfrak{R}$ be convex; then the points $\mathbf{x} \in \mathfrak{R}^{n}$ fulfilling condition $c(\mathbf{x}) \leq 0$ define a convex set. Let function $f: \mathfrak{R}^{n} \rightarrow \mathfrak{R}$ be convex and twice differentiable. A convex optimization problem has the form

$$
\begin{array}{ll}
\text { minimize } & f(\mathbf{x}) \\
\text { subject to } & c_{i}(\mathbf{x}) \leq 0 \quad i=1, \ldots, m
\end{array}
$$

namely, it is the problem of minimizing a convex objective function, subject to $m$ convex constraints. Unconstrained problems, i.e., $m=0$, can be reduced to solving a sequence of quadratic problems using the "Newton method." Problems with constraints, i.e., $m>0$, can be reduced to solving a sequence of unconstrained problems using any Interior Point method (IP), for instance the barrier method, or the primal-dual method. 
[9] In general, an IP method is an iterative procedure, where each step requires the calculation of the first and second-order derivatives of the objective functions and constraint functions, namely the $m+1$ gradients $\nabla f(\mathbf{x})$, $\nabla c_{i}(\mathbf{x})$, and the $m+1$ Hessians $\nabla^{2} f(\mathbf{x}), \nabla^{2} c_{i}(\mathbf{x})$. For many practical applications interior-point methods can solve the problem in a number of steps or iterations that is almost always in the range between 10 and 100 . Ignoring any structural peculiarity of the problem (such as sparsity), each step requires on the order of

$$
\max \left\{n^{3}, n^{2} m, F\right\}
$$

operations, where $F$ is the cost of evaluating the derivatives. Description of IP methods and descent methods, and further analysis of their complexity can be found in the work of Boyd and Vandenberghe [2004].

\section{Simulation}

[10] We consider a system composed of an aquifer, and $N$ pumping wells, which are connected to the Water Works distribution mains through a Water Distribution Network (WDN). In each well, the groundwater is lifted using an electric submersible pump, which is controlled by setting the rotational speed of the impeller. As pump setting, we consider a variable $a$ varying along the continuous interval $[0,1]$, having a one-to-one relationship with the rotational speed; i.e., $a=1$ is "maximum speed," and $a=0$ is 'pump switched off'. The WDN has $M$ nodes and one outlet $(M \geq N)$, which are indexed in a way so that node $i=0$ is the outlet, and the nodes from $i=1$ to $i=N$ are the ones connected to the pumping wells. We consider $K$ time steps of equal duration $\Delta t$, defining the management time horizon. A scheduling is a sequence of vectors $\mathbf{a}_{1}, \ldots, \mathbf{a}_{K}$, of pump setting values for the $N$ pumps $\mathbf{a}_{k}=\left(a_{1 k}, a_{2 k}, \ldots, a_{N k}\right)^{\top}$ at each time step $k$. The pump settings vector $\mathbf{a}_{k}$ is constant throughout the interval $[(k-1) \Delta t, k \Delta t)$. The pumping rate $q_{i k}$ of the $i$ th pump at time $k$, is function of the lifted head

$$
q_{i k}=g_{i}\left(a_{i k}, v_{i k}-h_{i k}\right)
$$

where $h_{i k}$ is the hydraulic head in the well, $v_{i k}$ is the hydraulic head at the $i$ th network node, and $g_{i}()$ the "pump characteristics" curve (or "head flow curve"), which is positive, invertible, and decreasing for fixed setting $a_{i k}$. Those curves are empirically derived by measuring different combinations of lift head and pump rate values under "Standard Conditions." The effect of the pump setting variation is to modify the pump characteristic curve, and this occurs with different mechanisms, depending on the pump model. In general, the effect of increasing $a_{i k}$, with constant head difference $v_{i k}-h_{i k}$, causes an increment of the pumping rate $q_{i k}$. Here the only assumption that we make is that $q_{i k}$ is continuous and monotonically increasing with $a_{i k}$. An example of pump characteristics is shown in Figure 1.

[11] The values of $h_{i k}$ and $v_{i k}$ depend on the groundwater hydraulics, the WDN hydraulics, and the way they interact. Let $w_{i j k}$ be the flowrate from node $i$ to node $j$ at time $k$; we conventionally consider as positive the flow direction from the high node index, to the low node index, i.e., $w_{i j k}>0$ if

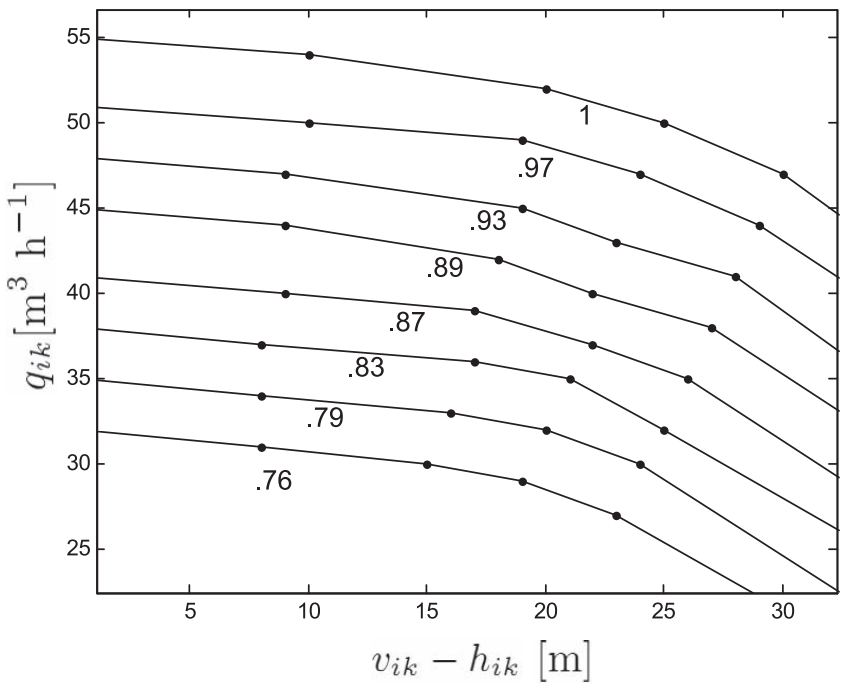

Figure 1. Example of characteristic curves for a commercial variable frequency drive pump. Each curve is labeled with the value of the corresponding pump setting $a_{i k} \in[0,1]$.

$i>j$ and $<0$ otherwise. The WDN is subject to the continuity equations

$$
\sum_{j=0}^{i} w_{j i k}-\sum_{j=i+1}^{M} w_{i j k}= \begin{cases}-\sum_{n=1}^{N} q_{n k}, & i=0(\text { outlet }) \\ q_{i k}, & 0<i \leq N(\text { pumps }) \\ 0, & N<i \leq M(\text { nodes })\end{cases}
$$

in every node $i=0,1, \ldots, M$, and the energy loss equations

$$
v_{i k}-v_{j k}=f_{i j}\left(w_{i j k}\right)
$$

in every pair of nodes $i, j=0, \ldots, M$. Functions $f_{i, j}$ depend on the pipe roughness and geometry, such as length, diameter, etc. If nodes $i, j$ are connected, function $f_{i j}$ is positive, nonlinear and convex $\left(d^{2} f_{i j} / d\left(w_{i j k}\right)^{2} \geq 0\right)$, and invertible. If nodes $i, j$ are not connected, function $f_{i j}$ is equal to zero. The outlet is a reservoir with constant level $v_{0}$. The water heads in the network nodes connected to the wells $\mathbf{v}_{k}=\left(v_{1 k}, \ldots, v_{N k}\right)^{\top}$ are obtained as function of the stresses $q_{1 k}, \ldots, q_{N k}$ by solving the nonlinear system of equations (3), (4), see e.g., Simpson and Elhay [2011]. This is herein summarized by the expression

$$
\mathbf{v}_{k}=\mathbf{V}\left(\mathbf{q}_{k}\right) .
$$

[12] The aquifer's water head response to the pump stresses is obtained by solving the equations governing the groundwater flow. We denote with $q_{i}(t)$ the continuoustime pumping stress in well $i$, and with $\mathbf{q}(t)=$ $\left(q_{1}(t), \ldots, q_{N}(t)\right)^{\top}$ the $N$ stresses. The continuous-time aquifer response to $\mathbf{q}(t)$ at well $i$ is the piezometric water level $h_{i}(t)$, and the collection of wells responses in continuous time is the vector $\mathbf{h}(t)=\left(h_{1}(t), \ldots, h_{N}(t)\right)^{\top}$. The aquifer's water head response to the pump stresses is described 
by the equations governing the groundwater flow (see e.g., Ahlfeld and Mulligan [2000]):

$$
S_{s} \frac{\partial h}{\partial t}=\nabla \cdot(\kappa \nabla h)+e+q
$$

where $S_{s}$ and $\kappa$ are the spatially variable specific storage coefficient $\left[\mathrm{L}^{-1}\right]$ and hydraulic conductivity tensor $\left[\mathrm{L} \mathrm{T}^{-1}\right]$, respectively. The term $e$ accounts for diffuse sources and sinks such as precipitation, evapotranspiration, and river/ lakes/sea level fluctuations. We consider $q(t)$ constant throughout each $\Delta t$ interval, and therefore equivalent to a discrete-time series of stresses $\mathbf{q}_{1}, \ldots, \mathbf{q}_{k}$. If both initial conditions and time-varying boundary conditions are known, the function $\mathbf{h}(t)$ and the corresponding discrete-time response $\mathbf{h}_{1}, \ldots, \mathbf{h}_{k}$, are obtained by numerical integration of equation (6). In the case of confined aquifer, this is equivalent of the explicit linear relationship

$$
h_{i k}=\sum_{j=1}^{N} \sum_{k^{\prime}=1}^{k} q_{j k^{\prime}} \theta_{i j, k-k^{\prime}+1}+b_{i k}
$$

where $\mathbf{b}_{k}=\left(b_{k 1}, \ldots, b_{k N}\right)^{\top}$ is the vector of the no-pumping heads. The constants $\theta_{i j, k-k^{\prime}+1}$, called Impulse Response Function (IRF), quantify the head response of well $i$ at time $k$ to a stress $j$ at time $k^{\prime} \leq k$. The IRF is always nonpositive, i.e.,

$$
\theta_{i j, k-k^{\prime}+1}=\frac{\partial h_{i k}}{\partial q_{j k^{\prime}}} \leq 0
$$

[13] We make the assumption that the response in drawdown of well $i$ to stress $i$ is much deeper than the response to stresses from other wells $i \neq j$

$$
\frac{\partial h_{i k}}{\partial q_{j k^{\prime}}} \gg \frac{\partial h_{i k}}{\partial q_{i k^{\prime}}} .
$$

This means that the Jacobian matrix $\partial \mathbf{h}_{k} / \partial \mathbf{q}_{k}$ is 'almost' diagonal and thus negative definite. In real life cases, this is always a realistic assumption (see e.g., Ahlfeld and Mulligan [2000]). Formula (7) can be performed efficiently, as the discrete IRF, $\theta_{i j k}$ can be determined at once for all $i, j, k$ and then stored into the computer memory. Such approach is known as the 'response matrix' approach [Gorelick, 1983].

[14] Discrete-time simulations of an aquifer-WDN system can be performed in two ways, depending on the input variable. One way is to determine the system response $\mathbf{v}_{1}, \ldots, \mathbf{v}_{K}, \mathbf{h}_{1}, \ldots, \mathbf{h}_{K}$, and the pumping stress series $\mathbf{q}_{1}, \ldots, \mathbf{q}_{K}$, as function of a given scheduling $\mathbf{a}_{1}, \ldots, \mathbf{a}_{K}$. The other way is to determine the scheduling and the system response, as function of a pumping stresses. Either ways, the simulation requires the ensemble of equations (2), (5), and (7) to be fulfilled. Note that the three equations are implicit in $a_{i k}$, therefore, when the pumping stress is the input, they must be solved as a whole nonlinear system. In the case where the input are instead the pumping stress, the three equations can be solved separately. In fact, the heads in the WDN are explicit function of the stresses through equation (5). Similarly, the heads in the aquifer are explicit function of the stresses through equation (7). Equation (2) is not necessary to determine the system response, but it is still needed to verify that the stresses are within the capacity of the pumps. In other words, the feasibility condition

$$
0 \leq q_{i k} \leq g_{i}\left(1, v_{i k}-h_{i k}\right) \quad \forall i, k
$$

must be fulfilled by the input stresses

\section{Management Problem}

[15] In this section we define a management model for a confined aquifer, where the well pumps are interconnected through a WDN that has no loops. This is the typical situation where the wells are deployed over a vast rural territory, and an unlooped pipeline is normally the most cost effective way to connect them to the Water Works mains. An important property of unlooped WDNs is that the heads are convex function of the stresses, namely function $v_{i k}=V_{i}\left(\mathbf{q}_{k}\right)$ is convex for all $i, k$. We provide the proof of this in Appendix A. The goal of the management is to fulfill a set of constraints, with minimum operational cost.

[16] We consider as operational cost of pump $i$ at time $k$, the amount of energy required to lift the water from the aquifer level $h_{i k}$ to the WDN node level $v_{i k}$ :

$$
p_{i k}=\frac{\Delta t \rho_{w}}{\eta_{i}} q_{i k}\left(v_{i k}-h_{i k}\right)
$$

where $\rho_{w}$ is the density of water $\left[\mathrm{M} \mathrm{L}^{-3}\right]$, and $\eta_{i}$ is the efficiency of the $i$ th pump [-]. The total operational cost $\mathcal{P}$ is the total amount of energy used in all pumps, during the entire management period

$$
\mathcal{P}=\sum_{k=1}^{K} \sum_{i=1}^{N} p_{i k}
$$

and it depends on the pump rates and the aquifer-WDN system response.

[17] Constraints may take the form of any function of the hydraulic head, stresses and time, (see e.g., Ahlfeld and Mulligan [2000]). Some examples are: stress bounds (e.g., $q_{i k} \leq \bar{q}_{k}$ ) accounting for the pumps maximum capacity or to meet regulation requirements; bounds on total stress (e.g., $\sum_{i=1}^{N} q_{i k} \geq d_{k}$ ) for water demand fulfillment; head bound constraints (e.g., $h_{i k} \leq \bar{h}_{i k}$ ) for mining and dewatering or subsidence control; head difference constraints (e.g., $\left.h_{i k}-h_{j k} \geq \Delta_{k}\right)$ to control salt water or polluted water intrusion within the aquifer. All these constraints, in confined aquifers, are linear function of the stresses. Here we consider the more generic case of a set of $N_{c}$ constraints in the form of convex nonlinear functions, denoted as

$$
c_{j k}\left(\mathbf{q}_{1}, \ldots, \mathbf{q}_{k}\right) \leq 0 \quad j=1, \ldots, N_{c} .
$$

[18] We refer to a set of inequalities (12) as "management constraints." 
[19] The optimal management solution is a scheduling $\mathbf{a}_{1}, \ldots, \mathbf{a}_{K}$, and the equivalent series of stresses $\mathbf{q}_{1}^{*}, \ldots, \mathbf{q}_{K}^{*}$, attaining the minimum total operational cost $\mathcal{P}^{*}$, while fulfilling the management constraints (12). Similarly as for the simulation problem described in section 3 , also the management problem can be formulated in two different ways, i.e., considering the scheduling or the stresses as decision variables. Here we want to investigate whether those two, equivalent, problems are convex, so they can be solved using IP methods.

[20] When the scheduling $\mathbf{a}_{1}, \ldots, \mathbf{a}_{K}$ is given, the total operational cost is obtained by fulfilling equations (2), (5), (7), (10), and (11):

$$
\begin{aligned}
\mathcal{P} & =\sum_{k=1}^{K} \sum_{i=1}^{N} \frac{\Delta t \rho_{w}}{\eta_{i}} q_{i k}\left(v_{i k}-h_{i k}\right) \\
q_{i k} & =g_{i}\left(a_{i k}, v_{i}-h_{i}\right) \\
h_{i k} & =\sum_{j=1}^{N} \sum_{k^{\prime}=1}^{k} q_{j k^{\prime}} q_{i j, k-k^{\prime}+1}+b_{i k} \\
v_{i k} & =V_{i}\left(\mathbf{q}_{k}\right)
\end{aligned}
$$

for all $i=1, \ldots, N_{c}$, and for all $k=1, \ldots, K$. Besides the computational burden of having to solve a large system of nonlinear equations in order to evaluate the objective function, this implicit relationship often causes $\mathcal{P}$ to be nonconvex with the decision variable. Clearly this may vary from case to case, and it may also depends on how the pump characteristics $g_{i}()$ depend on the pump settings $a_{i k}$. In general, however, the convexity of the objective function cannot be guarantee. Similarly, also the management constraints (12), which are implicit function of the decision variable, could be not convex. We conclude that IP methods do not guarantee optimality if the scheduling is the decision variable.

[21] When the pump rates $\mathbf{q}_{1}, \ldots, \mathbf{q}_{K}$ are the decision variable, the pump characteristics equations (2) are not needed to calculate the aquifer-WDN systems response, hence equations (5), (7), (10), and (11) can be put together into one explicit expression

$$
\begin{aligned}
\mathcal{P} & =\sum_{k=1}^{K} \sum_{i=1}^{N} \frac{\Delta t \rho_{w}}{\eta_{i}} q_{i k}\left(v_{i k}-h_{i k}\right) \\
q_{i k} & =g_{i}\left(a_{i k}, v_{i}-h_{i}\right) \\
h_{i k} & =\sum_{j=1}^{N} \sum_{k^{\prime}=1}^{k} q_{j k^{\prime}}\left(_{i j, k-k^{\prime}+1}+b_{i k}\right. \\
v_{i k} & =V_{i}\left(\mathbf{q}_{k}\right)
\end{aligned}
$$

The convexity of (13) can be proved based on the convexity of $V_{i}\left(\mathbf{q}_{k}\right)$, and the fact that the Jacobian matrix $\partial \mathbf{h}_{k} / \partial \mathbf{q}_{k}$ is negative definite. Also this proof is in Appendix A.

[22] Besides the management constraints $c_{i}()$, that are convex with the stresses, the problem definition also requires the stresses to be within the capacity of the pumps, hence conditions (9) must be included within the set of constraints, and their convexity must be proved.
[23] We reformulate the pumps capacity constraints, considering that function $g_{i}()$ is invertible within the pump's range,

$$
0 \leq v_{i k}-h_{i k} \leq g_{i}^{-1}\left(1, q_{i k}\right) \quad \forall i, k
$$

Expressions (14) and (9) are equivalent, as they both imply the point $\left(v_{i k}-h_{i k}, q_{i k}\right)$ to have positive coordinates, and be underneath the pump characteristic curve, as illustrated on Figure 2. The left-hand side of condition (14)

$$
v_{i k} \geq h_{i k} \quad \forall i, k
$$

can be ignored, as there is no reason to expect the aquifer's head $h_{i k}$ to exceed or even just to approach the head levels in the network nodes $v_{i k}$. The right-hand side of equation (14)

$$
v_{i k}-h_{i k}-g_{i}^{-1}\left(1, q_{i k}\right) \leq 0 \quad \forall i, k
$$

defines what we call "network constraints." As mentioned at the beginning of this section $v_{i}=V_{i}\left(\mathbf{q}_{k}\right)$ is a convex function. The aquifer heads in the wells $h_{i k}$ are also convex, as linear function of the stresses, therefore the condition for the constraint (15) to be convex is that $-g_{i}^{-1}\left(1, q_{i k}\right)$ is convex. Conversely $g_{i}()$ must be concave.

[24] Although in principle this should reflect the true geometry of the pump characteristics, in reality those curves sometimes are not perfectly concave. This concept is clarified in section 5. In this section, perfect concavity of the pumps characteristic is assumed, hence the resulting problem formulation

$$
\mathcal{P}^{*}=\min _{\mathbf{q}_{1}, \ldots, \mathbf{q}_{K}} \sum_{k=1}^{K} \sum_{i=1}^{N} \frac{\Delta t \rho_{w}}{\eta_{i}} q_{i k}\left(v_{i k}-h_{i k}\right)
$$

subject to:

$$
\begin{aligned}
& v_{i k}=V_{i}\left(\mathbf{q}_{k}\right) \\
& h_{i k}=\sum_{j=1}^{N} \sum_{k^{\prime}=1}^{k} q_{j k^{\prime}} \theta_{i j, k-k^{\prime}+1}+b_{i k} \\
& c_{j k}\left(\mathbf{q}_{1}, \ldots, \mathbf{q}_{k}\right) \leq 0 \\
& v_{i k}-g_{i}^{-1}\left(1, q_{i k}\right)-h_{i k} \leq 0
\end{aligned} \quad j=1, \ldots, N_{c}
$$

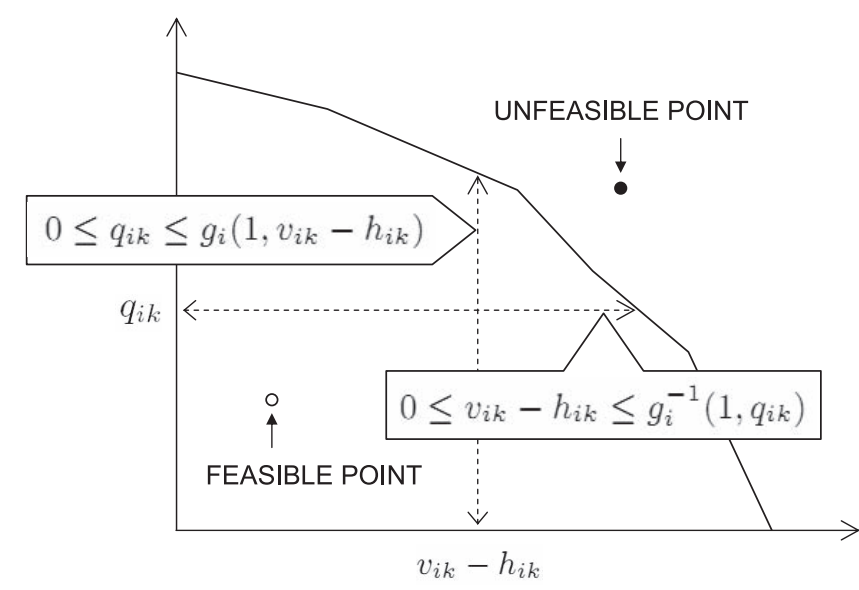

Figure 2. Two equivalent formulations of the pumps capacity constraints. A point is feasible if it has positive coordinates $\left(v_{i k}-h_{i k}, q_{i k}\right)$, and it lies below the line $q_{i k}=g_{i}\left(1, v_{i k}-h_{i k}\right)$. 
is a problem of convex optimization having $N K$ decision variables, and $\left(N_{c}+N\right) K$ constraints. The problem can be solved using IP methods, yielding the optimal stresses $\mathbf{q}_{1}^{*}, \ldots, \mathbf{q}_{K}^{*}$. The corresponding optimal scheduling $\mathbf{a}_{1}^{*}, \ldots, \mathbf{a}_{K}^{*}$ is obtained from the characteristics solving equation

$$
q_{i k}^{*}=g_{i}\left(a_{i k}^{*}, V_{i}\left(\mathbf{q}_{k}^{*}\right)-\sum_{j=1}^{N} \sum_{k^{\prime}=1}^{k} q_{j k^{\prime}} \theta_{i j, k-k^{\prime}+1}-b_{i k}\right)
$$

for all $i=1, \ldots, N$ and $k=1, \ldots, K$. Equation (18) has one solution, as for given stresses, the head difference $v_{i k}-h_{i k}$ is given, thus $a_{i k}$ is monotonic with $q_{i k}$.

\section{Suboptimality and Bounds}

[25] The applicability of IP methods to yield the optimal solution of the management problem (16) s.t. (17), is subject to the condition that $-g_{i}^{-1}\left(1, q_{i k}\right)$ is convex, or equivalently, that full-speed pump characteristics $g_{i}\left(1, v_{i k}-h_{i k}\right)$ are concave.

[26] For a fixed setting $a_{i k} \in[0,1]$, pumps characteristics $g_{i}\left(a_{i k}, v_{i k}-h_{i k}\right)$ are curves that typically decrease more than linearly with $v_{i k}-h_{i k}$, meaning that either they are concave, or they can be well approximated by concave functions. When the case is the latter, characteristics can be described as slightly undulating lines following the pattern of a some concave functions, (Figure 1). More formally, in this case, characteristics are said to be almost concave curves, and function $-g_{i}^{-1}\left(1, q_{i k}\right)$ are almost convex [Bot et al., 2007]. We denote with $-G_{i}^{-1}\left(q_{i k}\right)$. The largest convex function not exceeding $-g_{i}^{-1}\left(1, q_{i k}\right)$, or its 'convex hull function'. Let $\delta_{i}$ be the distance

$$
\delta_{i}=\max _{q}\left(-g_{i}^{-1}(1, q)+G_{i}^{-1}(q)\right)
$$

then the almost convex function $-g_{i}^{-1}\left(1, q_{i k}\right)$ is bounded between two convex functions being $\delta_{i}$ apart

$$
-G_{i}^{-1}\left(q_{i k}\right)+\delta_{i} \leq-g_{i}^{-1}\left(1, q_{i k}\right) \leq-G_{i}^{-1}\left(q_{i k}\right)
$$

as illustrated in Figure 3. The distance $\delta_{i}$ is a measure of the closeness to convexity, if $-g_{i}^{-1}\left(1, q_{i k}\right)$ is convex, then $\delta_{i}=0$, hence $-g^{-1}\left(1, q_{i k}\right)=-G_{i}^{-1}\left(q_{i k}\right)$.

[27] When the assumption of perfect concavity of the pumps characteristic is not valid, then the network constraints (15) are almost convex, hence the management problem is not convex. Here we define the alternative convex problem by replacing the network constraints (17) with the (convex) condition

$$
\begin{aligned}
& v_{i k}=V_{i}\left(\mathbf{q}_{k}\right) \\
& h_{i k}=\sum_{j=1}^{N} \sum_{k^{\prime}=1}^{k} q_{j k^{\prime}} \theta_{i j, k-k^{\prime}+1}+b_{i k} \\
& c_{j k}\left(\mathbf{q}_{1}, \ldots, \mathbf{q}_{k}\right) \leq 0 \\
& v_{i}-h_{i k}-G_{i}^{-1}\left(q_{i k}\right)+\delta_{i} \leq 0
\end{aligned} \quad j=1, \ldots, N_{c}
$$

we denote with $\overline{\mathbf{q}}_{1}, \ldots, \overline{\mathbf{q}}_{K}$ the optimal stresses, and with $\overline{\mathcal{P}}$ the objective function value. We note that the domain of

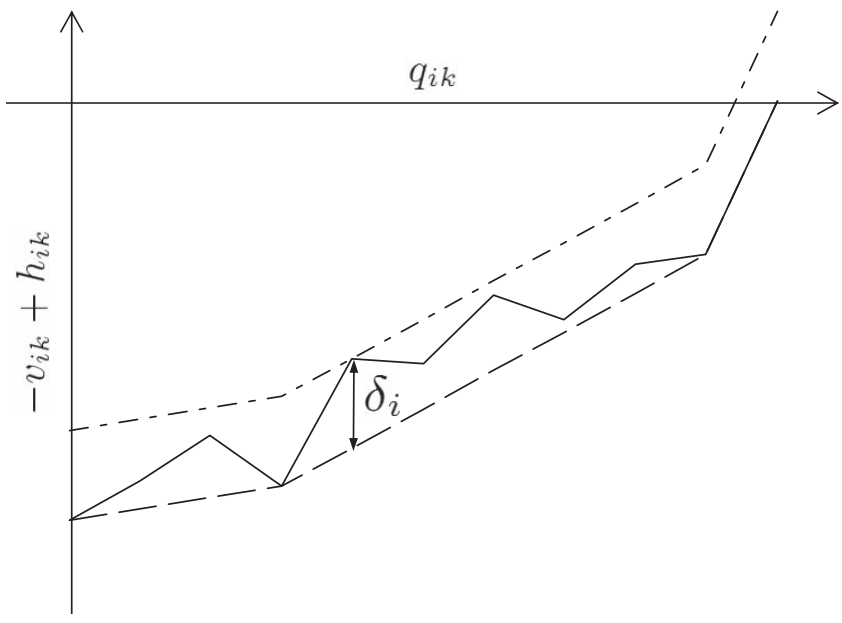

Figure 3. Example of convex hull function (dashed line) of a generic function (solid line). The distance $\delta_{i}$ is a measure of the closeness to convexity.

$D^{\prime} \subset \mathfrak{R}^{N K}$ fulfilling conditions (19) is entirely included within the domain $D \subset \mathfrak{R}^{N K}$ fulfilling the network constraints (17), namely $D^{\prime} \subseteq D$. Considering that the optimal scheduling $\mathbf{q}_{1}^{*}, \ldots, \mathbf{q}_{k}^{*} \in D$ attains the minimum (16) on both $D$ and $D^{\prime}$, if $\mathbf{q}_{1}^{*}, \ldots, \mathbf{q}_{k}^{*} \in D / D^{\prime}$, then the stresses $\overline{\mathbf{q}}_{1}, \ldots, \overline{\mathbf{q}}_{K}$ are suboptimal. Consequently $\overline{\mathbf{q}}_{1}, \ldots, \overline{\mathbf{q}}_{K}$ is certainly feasible for problem (16) s.t. (17), and $\overline{\mathcal{P}}$ is at most as good as the optimum, i.e., $\overline{\mathcal{P}} \geq \mathcal{P}^{*}$. We argue that the shape of $-g_{i}^{-1}\left(1, q_{i k}\right)$ for commercial pumps are typically either convex, or almost convex curves with small $\delta_{i}$. Consequently we would expect the distance between $\overline{\mathcal{P}}$ and $\mathcal{P}^{*}$ to be small. Although we cannot determine this distance, we can use the same approach to estimate an upper bound of it, namely an $\epsilon \geq 0$ such that $\overline{\mathcal{P}} \geq \mathcal{P}^{*} \geq$ $(1-\epsilon) \overline{\mathcal{P}}$.

[28] We solve problem (16) subject to the following constraints

$$
\begin{array}{ll}
v_{i k}=V_{i}\left(\mathbf{q}_{k}\right) & \\
h_{i k}=\sum_{j=1}^{N} \sum_{k^{\prime}=1}^{k} q_{j k^{\prime}} \theta_{i j, k-k^{\prime}+1}+b_{i k} & \\
c_{j k}\left(\mathbf{q}_{1}, \ldots, \mathbf{q}_{k}\right) \leq 0 & j=1, \ldots, N_{c} \\
v_{i}-h_{i k}-G_{i}^{-1}\left(q_{i k}\right) \leq 0 &
\end{array}
$$

Similarly to the previous argument, the domain of $D^{\prime \prime} \subset \mathfrak{R}^{N K}$ fulfilling conditions (20) entirely contains the domain $D^{\prime} \subset \mathfrak{R}^{N K}$ fulfilling (19), namely $D^{\prime \prime} \subseteq D^{\prime}$. Then the optimal solution of problem (16) s.t. (20) has a total energy consumption that is at most as great as $\overline{\mathcal{P}}$, hence it is equal to $(1-\epsilon) \overline{\mathcal{P}}$, with $\epsilon \geq 0$. The same domain also contains $D$, namely, $D^{\prime \prime} \subseteq D \subseteq D^{\prime}$, then $(1-\epsilon) \overline{\mathcal{P}}$ is at most as great as $\mathcal{P}^{*}$, hence $(1-\epsilon) \overline{\overline{\mathcal{P}}} \leq \mathcal{P}^{*}$. Suboptimal solutions will be close to optimal if $\epsilon$ is small. Clearly, the more $-g_{i}^{-1}\left(1, q_{i k}\right)$ are similar to the convex hull function $-G_{i}^{-1}\left(q_{i k}\right)$, namely the smaller the values of $\delta_{i}, i=$ $1, \ldots, N$, the smaller $\epsilon$.

[29] Suppose the bound is loose, for instance $\epsilon=.05$. Then in the worst case scenario, the minimum total energy $\mathcal{P}^{*}$ could be up to $5 \%$ less than $\overline{\mathcal{P}}$, and it would be worth 
trying to improve the solution using some local search algorithm, i.e., attempting to solve problem (16) s.t. (17), by starting from $\overline{\mathbf{q}}_{1}, \ldots, \overline{\mathbf{q}}_{K}$ as initial guess. The local search may be performed by any heuristics, such as Genetic Algorithms. Here we use a simple gradient descent

$$
\begin{aligned}
& \text { repeat } \\
& \text { 1. } \Delta \overline{\mathbf{q}}_{k}:=-\nabla \mathcal{P}\left(\overline{\mathbf{q}}_{k}\right) \text { for All } k \\
& \text { 2. } \overline{\mathcal{P}}:=\min _{t} \mathcal{P}\left(\overline{\mathbf{q}}_{1}+t \Delta \overline{\mathbf{q}}_{1}, \ldots, \overline{\mathbf{q}}_{K}+t \Delta \overline{\mathbf{q}}_{K}\right) \\
& \text { subject to : } \\
& v_{i k}=V_{i}\left(\overline{\mathbf{q}}_{k}+t \Delta \overline{\mathbf{q}}_{k}\right) \\
& h_{i k}=\sum_{j=1}^{N} \sum_{k^{\prime}=1}^{k}\left(\bar{q}_{j k^{\prime}}+t \Delta \bar{q}_{j k^{\prime}}\right) \theta_{i j, k-k^{\prime}+1}+b_{i k} \\
& c_{j k}\left(\overline{\mathbf{q}}_{1}+t \Delta \overline{\mathbf{q}}_{1}, \ldots, \overline{\mathbf{q}}_{K}+t \Delta \overline{\mathbf{q}}_{K}\right) \leq 0 ; \quad j=1, \ldots, N_{c} \\
& v_{i}-h_{i k}-g_{i}^{-1}\left(1, \bar{q}_{j k^{\prime}}+t \Delta \bar{q}_{j k^{\prime}}\right) \leq 0 \\
& \text { 3. } \overline{\mathbf{q}}_{k}:=\overline{\mathbf{q}}_{k}+t \Delta \overline{\mathbf{q}}_{k} \\
& \text { until } t=0 \text {, }
\end{aligned}
$$

where $\mathcal{P}$ is optimized along the gradient direction, until the boundaries of the feasible space defined by constraints (17) are reached. So in this case the IP methods are used as the global portion of a local-global search algorithm.

\section{Implementation of the Methodology}

[30] The described methodology is implemented and included within the WELLNES software package (A. Falk and H. Madsen, A well field model based on a dynamic coupling between a pipe network model and a groundwater model, submitted to Environmental Modelling Software, 2012). WELLNES contains and coordinates the interactions between a physically based groundwater model (MIKE-SHE) [Graham and Butts, 2006], and a WDN model (EPANET, Rossman [2000]). MIKE-SHE simulates dynamic exchange of water between all major hydrological components, e.g., surface water, soil water and groundwater. It solves basic equations governing the major flow processes within the study area. The spatial and temporal variation of meteorological, hydrological, geological and hydrogeological data across the model area is described in gridded form for the input as well as the output from the model. EPANET is a computer program that performs extended period simulation of hydraulic behavior within pressurized pipe networks. It is released by the United States Environmental Protection Agency, and it is freely distributed.

[31] In a groundwater model, wells are simulated as sink terms (equation (6)) in a numerical cell (A. Falk and $\mathrm{H}$. Madsen, submitted, 2012). This ensures a correct water balance but does not give a good representation of the water level in the well.

[32] Close to a well there is a steep gradient in hydraulic head, which would require a high resolution for the groundwater model to resolve, increasing accuracy then increases computational complexity. WELLNES overcomes this problem, by interposing a well drawdown engine, named WELL, which is based on the same equations as used by the drawdown-limited MODFLOWs Multi-Node Well package [Halford and Hanson, 2002]. A head loss equation is set up for each cell penetrated by the well. The system of equations is closed with the condition that the sum of flows from each cell equals the total extraction from the well.
The equations are the same, but the implementation differs from that in MODFLOW, as the present implementation uses the cell head calculated by the groundwater model in the former time step and the pump flow for the current time step as forcings. The WELL engine predicts the water drawdown without requiring a high model resolution around the wells.

[33] WELLNES is equipped with a library, called OPTIWELL, for solving optimal management problems in confined aquifers, described in section 4. The OPTIWELL workflow, illustrated in Figure 4, is a framework iterating through three distinct phases: (1) preprocessing, (2) optimization, (3) scheduling. Preprocessing: MIKE-SHE computes the impulse response functions $\theta_{i j k}$ and heads $b_{i k}$ by measuring, using MIKE-SHE simulations, the aquifer response at wells to impulse pump signals. Procedures to derive IRFs using a simulation model are described by Heidari [1982]. In this phase, Assumption of perfect concavity of the pumps characteristic is checked; the convex hull function $-G_{i}^{-1}\left(q_{i k}\right)$ is constructed using the characteristics of the pumps connecting the WDN, and the closeness $\delta_{i}$ of the network constraints to convexity is measured. Optimization: OPTIWELL solves the management problem of equation (16) s.t. constraints (19). The IP method used is the barrier method, a comprehensive description of this method can be found in the book by Boyd and Vandenberghe [2004]. If the network constraints are not convex, the solution $\overline{\mathbf{q}}_{1}, \ldots, \overline{\mathbf{q}}_{K}$ coincides with the optimal stresses $\mathbf{q}_{1}^{*}, \ldots, \mathbf{q}_{K}^{*}$, hence the solution of the original problem (16) s.t. (17). If the network constraints are convex, $\overline{\mathbf{q}}_{1}, \ldots, \overline{\mathbf{q}}_{K}$ is improved using the local search scheme described in section 5 . The assessment of a lower bound $(1-\epsilon) \overline{\mathcal{P}} \leq \mathcal{P}^{*}$ is computed using IP methods to solve problem (16) s.t. (20). Scheduling: OPTIWELL computes the scheduling from the optimal (or suboptimal) stresses solving equation (18).

[34] Normally, the preprocessing is done only at once, to set up the case study (see Figure 4). Solving the same problem for different sets of constraints and/or pumps models only requires optimization and scheduling. Preprocessing is only required again when the case study changes. For instance, to consider different boundary conditions (rain, surface water, barometric pressure, etc.), or to include more wells, or to move wells to different positions. Section 7 describes the application of WELLNES in a real case study.

\section{Søndersø Case Study}

[35] The methodology described in this paper is tested in a part of the well field of Søndersø, located northwest of Copenhagen (DK) with an annual discharge of $5.3 \times 10^{6} \mathrm{~m}^{3}$ of water. The system comprises two groups of pumping wells, connected in series by a WDN. As shown in Figure 5, there are 9 wells located in the East (labeled starting with ' $\varnothing$ '), and 3 located in the West (V1A,V2A,V3A), for a total of $N=11$ pumping wells. The groundwater model is a local model nested within a regional model, Kürstein et al. [2009].

[36] The local model covers approximately an area of $4.3 \times 3.7 \mathrm{~km}$, and the grid size is $50 \mathrm{~m}$. The model contains 8 geological layers (five different clay layers, a sand layer and two limestone layers). As it can be seen in Figure 6, the pumping is mainly done from the chalk layers and partly from the sand layer; the aquifer is confined.

[37] The simulation period is 8 days from 18 December 2001 00:00 to 26 December 2001 00:00, the initial 


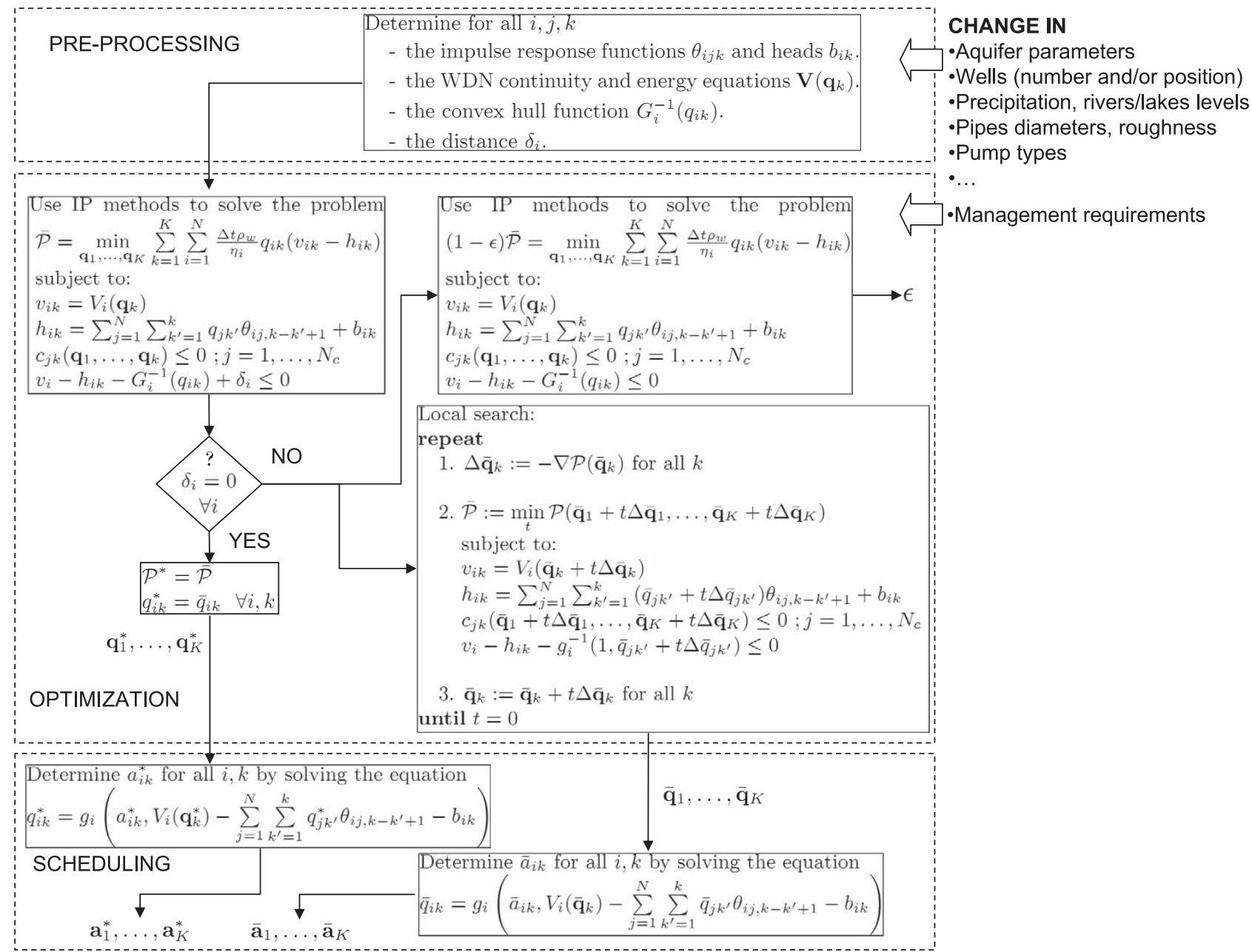

Figure 4. The OPTIWELL workflow for well field optimization.

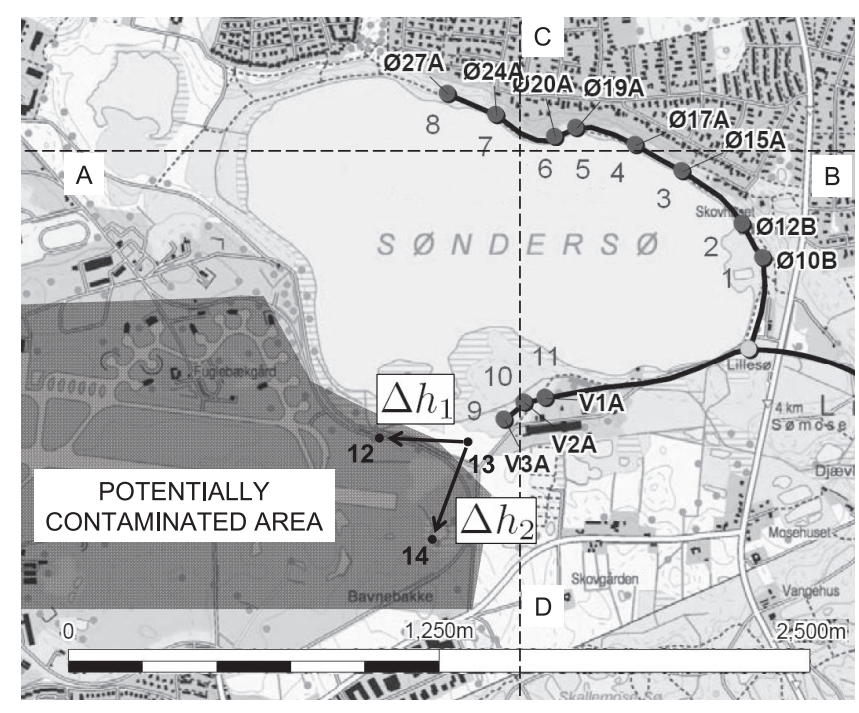

Figure 5. The Søndersø well field. condition is provided by a regional model (December 2001). There are 4 different types of variable frequency drive; their specifications are in Table 1. For those pumps setting $a_{i k} \in[0,1]$ represents a fraction of maximum capacity, namely,

$$
q_{i k}=g_{i}\left(a_{i k}, v_{i k}-h_{i k}\right)=a_{i k} \cdot g_{i}\left(v_{i k}-h_{i k}\right)
$$

for all $i$. The characteristics $g_{i}\left(v_{i k}-h_{i k}\right)$ are almost concave, hence $-g_{i}^{-1}\left(q_{i k}\right)$ are almost convex. The closeness to convexity can be observed in Figure 7, where all curves are tightly bounded between the convex hull function $-G_{i}^{-1}\left(q_{i k}\right)$ and the translated $-G_{i}^{-1}\left(q_{i k}\right)+\delta_{i}$.

[38] In what follows the management problem is defined and solved using the scheme in Figure 4, determining the optimized stresses $\overline{\mathbf{q}}_{1}, \ldots, \overline{\mathbf{q}}_{K}$, the total energy consumption $\overline{\mathcal{P}}$, and the optimality lower bound $(1-\epsilon) \overline{\mathcal{P}}$. The benefit of accounting for the WDN in optimization, can be here assessed by comparison with the results obtained solving 

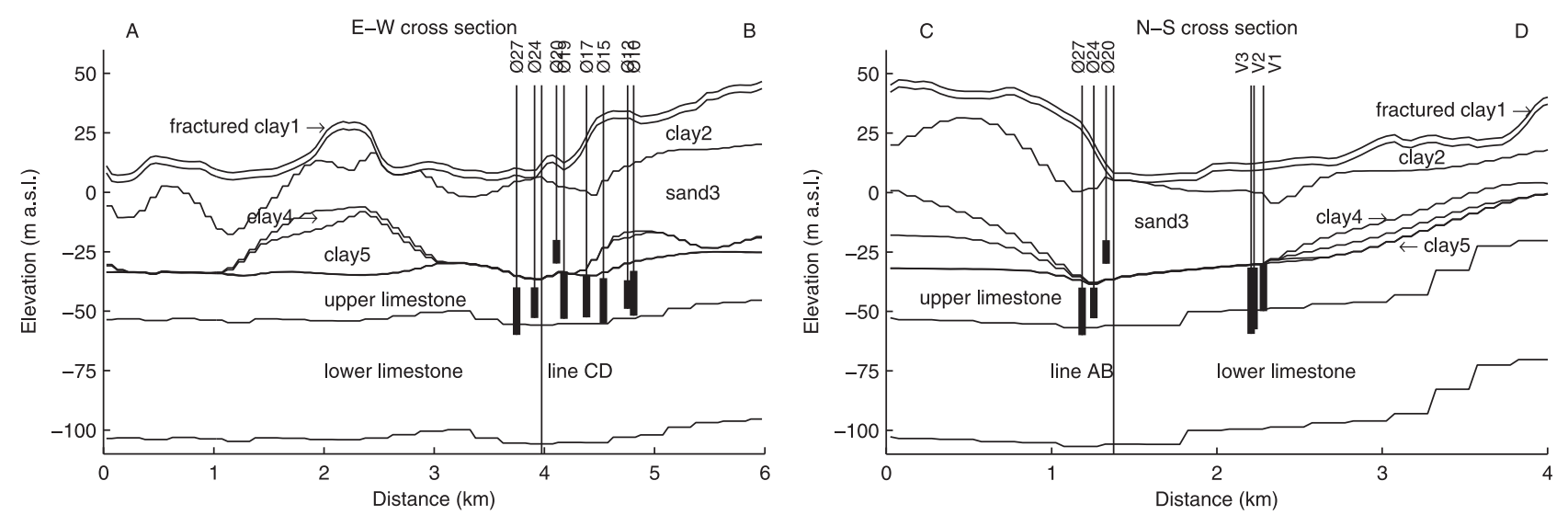

Figure 6. Cross sections along the lines $\mathrm{AB}$ and DC of Figure 5. Wells positions and filter depth are shown.

the same problem but without considering the WDN. Namely, we solve a problem

$$
\tilde{\mathbf{q}}_{1}, \ldots, \tilde{\mathbf{q}}_{K}=\arg \operatorname{mim}_{q_{1}, \ldots, q_{K}} \sum_{k=1}^{K} \sum_{i=1}^{N} \frac{\Delta t \rho_{w}}{\eta_{i}} q_{i k}\left(v_{i k}-h_{i k}\right)
$$

subject to:

$$
\begin{aligned}
& v_{i k}=v_{0} \\
& h_{i k}=\sum_{j=1}^{N} \sum_{k^{\prime}=1}^{k} q_{j k^{\prime}} \theta_{i j, k-k^{\prime}+1}+b_{i k} \\
& c_{j k}\left(\mathbf{q}_{1}, \ldots, \mathbf{q}_{k}\right) \leq 0 \quad j=1, \ldots, N_{c}
\end{aligned}
$$

where the WDN node heads $v_{i k}$ are replaced by the fixed outlet level $v_{0}$. The total energy consumption $\tilde{\mathcal{P}}$ is obtained by simulating the stresses $\tilde{\mathbf{q}}_{1}, \ldots, \tilde{\mathbf{q}}_{K}$ in the aquifer-WDN system, i.e., $\mathcal{P}=\mathcal{P}\left(\tilde{\mathbf{q}}_{1}, \ldots, \tilde{\mathbf{q}}_{K}\right)$. We then compare $\overline{\mathcal{P}}$ with $\tilde{\mathcal{P}}$, and $\overline{\mathbf{q}}_{1}, \ldots, \overline{\mathbf{q}}_{K}$ with $\tilde{\mathbf{q}}_{1}, \ldots, \tilde{\mathbf{q}}_{K}$. Furthermore, we also verify whether or not $\tilde{\mathbf{q}}_{1}, \ldots, \tilde{\mathbf{q}}_{K}$ fulfills the network constraints $V_{i}\left(\mathbf{q}_{k}\right)-g_{i}^{-1}\left(q_{i k}\right)-h_{i k} \leq 0$, as they are not included within the constraint set (21).

[39] We consider a water supply problem with fixed water demand $d$ over the management period. There is an old military airfield, located west of the well field, which is known to be contaminated, although the extent of the contamination is unknown. The well field abstracts water from a large area, and thus it is exposed to the risk of pollution from the airfield. A sustainable management strategy should take this into account. We do this by imposing head difference constraints over three monitoring wells numbered as 12, 13 and 14, (see Figure 5), respectively. Two head difference constraints are defined, $\Delta h_{1}$, between wells 13-12, and $\Delta h_{2}$, between wells 13-14, respectively.

Table 1. Pump Specification in Søndersø Well Field

\begin{tabular}{lcccc}
\hline \multicolumn{1}{c}{ Wells } & Type & Capacity $\left[\mathrm{m}^{3} \mathrm{~d}^{-1}\right]$ & $\eta$ & $\delta[\mathrm{m}]$ \\
\hline $1,2,4,5,8,9,11$ & SP77-4 & 2449 & 0.79 & 0.57 \\
3,6 & SP30-4 & 2421 & 0.78 & 1.14 \\
7 & SP46-5 & 941 & 0.7 & 0.33 \\
10 & SP60-4 & 2419 & 0.7 & 1.60 \\
\hline
\end{tabular}

[40] In summary, for each time step $k=1, \ldots, K$, there are $N_{c}=3$ management constraints, which are linear inequalities

$$
\begin{gathered}
c_{1}\left(\mathbf{q}_{k}\right)=d-\sum_{i=1}^{N} q_{i k} \leq 0, \\
c_{2}\left(\mathbf{q}_{1}, \ldots, \mathbf{q}_{k}\right)=-h_{13, k}+h_{12, k}+\Delta h_{1} \leq 0, \\
c_{3}\left(\mathbf{q}_{1}, \ldots, \mathbf{q}_{k}\right)=-h_{13, k}+h_{14, k}+\Delta h_{2} \leq 0 .
\end{gathered}
$$

We solve the problem for different values of demand $d$, while imposing the head difference constraints (23) and (24) to be non negative, hence $\Delta h_{1}=\Delta h_{2}=0$ meters. Clearly this is a simplification as in actual practice, one would use a "safety factor," and also impose several head difference constraints, to assure that contamination does not pose a threat.

[41] Table 2 shows the results of the management problem with $K=31$ decision time steps with duration $\Delta t=6 \mathrm{~h}$, for

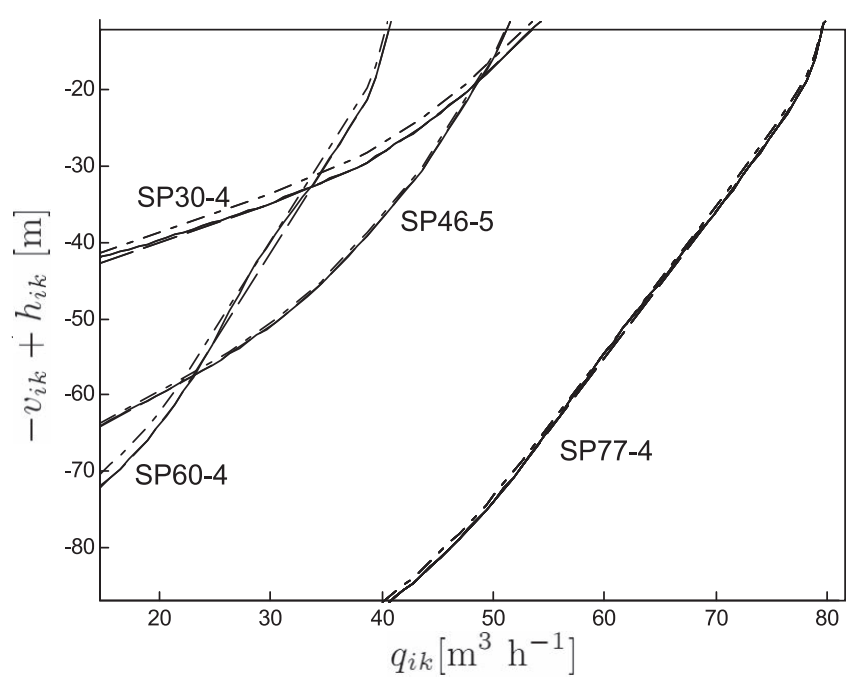

Figure 7. Solid lines are $-g_{i}^{-1}\left(q_{i k}\right)$ curves of the four pump models installed in Søndersø. Dashed curves are the convex hull functions $-G_{i}^{-1}\left(q_{i k}\right)$. Dash-dotted curves are upper convex bounds $-G_{i}^{-1}\left(q_{i k}\right)+\delta_{i}$. 
Table 2. Results of Management Optimization in Søndersø With $K=31$ Time Steps ${ }^{\mathrm{a}}$

\begin{tabular}{|c|c|c|c|c|c|}
\hline \multirow[b]{2}{*}{$d\left[\mathrm{~m}^{3} \mathrm{~s}^{-1}\right]$} & \multicolumn{3}{|c|}{ Considering the WDN } & \multicolumn{2}{|c|}{ Neglecting the WDN } \\
\hline & $\overline{\mathcal{P}}\left[\mathrm{kWh} \mathrm{m}^{-3}\right]$ & WDN Overhead [\%] & $\epsilon[\%]$ & $\tilde{\mathcal{P}}\left[\mathrm{kWh} \mathrm{m}^{-3}\right]$ & Violated Constraints [\%] \\
\hline 0.05 & 0.127 & 18.12 & 0 & $0.127(+0.09 \%)$ & 0 \\
\hline 0.08 & 0.157 & 21.41 & 0 & $0.157(+0.22 \%)$ & 0 \\
\hline 0.1 & 0.177 & 23.26 & 0.024 & $0.177(+0.21 \%)$ & 8.2 \\
\hline 0.12 & 0.197 & 24.65 & 0.016 & $0.198(+0.51 \%)$ & 8.5 \\
\hline 0.15 & 0.228 & 26.09 & 0.02 & $0.231(+0.94 \%)$ & 17.3 \\
\hline 0.16 & 0.239 & 26.41 & 0.025 & $0.241(+0.92 \%)$ & 26.7 \\
\hline 0.17 & 0.249 & 26.69 & 0.025 & $0.251(+0.88 \%)$ & 27.3 \\
\hline 0.18 & 0.259 & 26.93 & 0.025 & $0.261(+0.76 \%)$ & 31.7 \\
\hline
\end{tabular}

${ }^{\text {a }}$ Numbers in brackets are the percentage difference between $\tilde{\mathcal{P}}$ and $\overline{\mathcal{P}}$. The violated constraints are the percentage of the $N K=341$ network constraints.

a total time horizon of $K \cdot \Delta t=7.75$ days. The problem has $N K=11 \times 31=341$ decision variables, and $\left(N_{c}+N\right)$ $K=(3+11) \times 31=434$ constraints. We notice that, due to the nonlinearity of the objective function $\overline{\mathcal{P}}$ with the stresses, the energy cost per unit of water volume grows with the total pump rate. Also the WDN overhead, calculated as the difference between $\overline{\mathcal{P}}$ and the energy that would be ideally required to lift the groundwater from $h_{i k}$ to the outlet level $v_{0}$, grows with the demand. When the demand exceeds the $0.15 \mathrm{~m}^{3} \mathrm{~s}^{-1}$, the network overhead impacts for more than $25 \%$ of the entire energy use, hence the WDN has a very significant impact the management cost. Even though assumption of perfect concavity of the pumps characteristic is not valid and thus the suboptimal procedure described in section 5 was employed, the obtained solutions are always within a fraction of a percentage point of the optimal solution $(\epsilon<0.00025)$.

[42] The effect of not considering the WDN in optimization, results in a deterioration of the performance, as $\tilde{\mathcal{P}}$ is consistently larger than $\overline{\mathcal{P}}$. Although such difference is modest, (less than 1\%), the difference in shape of the pumping stresses pattern patterns shown in Figure 8 is significant. This suggests that the optimal solution is sensitive to the WDN topology, and even though in terms of total energy use the difference is negligible, for a larger case study we would expect to see this difference spreading. More importantly, Table 2 shows that $\tilde{\mathbf{q}}_{1}, \ldots, \tilde{\mathbf{q}}_{K}$ violates the network constraints, as $d$ increases. In fact, as the pumps' working regime approach the maximum capacity, the trajectories $\left(q_{i k}, v_{i k}-h_{i k}\right)$ tend to exceed the network constraint boundaries. This can be observed in Figure 9, showing a case when the WDN is excluded from the optimization, causing the network constraints to be violated at each time step for wells $3,6,7$, and 10 . We conclude that not considering the WDN within the optimization may yield management solutions that are not realistic, as they may not be feasible for the WDN.

[43] Some consideration regarding computational aspects of the proposed methodology can be done by observing the experimental data in Table 3 . The IP method used, the barrier method, required a number of Newton step iterations which turned out to be weakly dependent on the number of decision variables and constraints. In fact, with increasing length of the management time horizon $K$, and varying values of water demand $d$, the number of required iterations is always around $70-100$. Clearly for problems with larger number of wells and management time steps, we would eventually expect the number of iterations to increase. For a medium size problem, such as the presented case study, the time taken for optimization was mainly influenced by the time $F$ to compute the objective function, the constraints functions and their first and second-order derivatives (see section 2). The measurement reported in Table 3 refer to a personal computer with an Intel Core 2 Duo CPU $2.40 \mathrm{GHz} 790 \mathrm{MHz}, 2.99 \mathrm{~GB}$ RAM. For the larges case analyzed, $K=31$ optimization took less than $25 \mathrm{~s}$.

\section{Discussion and Conclusions}

[44] A methodology for multiperiod optimal management of systems of confined aquifers interacting with an unlooped pressurized Water Distribution Network (WDN), has been presented and discussed. Discrete-time simulations of an aquifer-WDN system require the WDN continuity and the energy equations to be solved altogether with the groundflow equation, and with the pumps characteristic equations. The type of pumps here considered are "Variable Speed," also called "Variable Frequency Drive Pumps." The shape of the characteristic curves of those pumps can be modified by operating the pumps settings. The system can be either controlled in terms of pumps settings, regulating the characteristic curves, or in terms of pumping stresses. As described in section 3 , if one wants to simulate an input series of pump settings (scheduling), the three sets of equations must be solved as a whole system of nonlinear equations. If the input is a series of pumping stresses, then the WDN and the groundflow equation can be solved separately, and the pump characteristics are not needed to determine the system response. However they are still necessary to verify the feasibility of the input pumping stresses, which must be within the capacity of the pumps.

[45] In section 4, the groundwater management problem was formulated as a minimum operational cost, subject to constraints, for a system of a confined aquifer, connected to WDN which has no loops. The applicability of IP methods was assessed by investigating the conditions, under which the problem is convex. The conditions identified are: the decision variable must be the stresses, and not the settings; the management constraints must be convex function of the stresses; and the pump characteristic curves must be concave function of the head difference. This latter condition was discussed in section 5, arguing that even when the characteristics curves of commercial pumps are not 

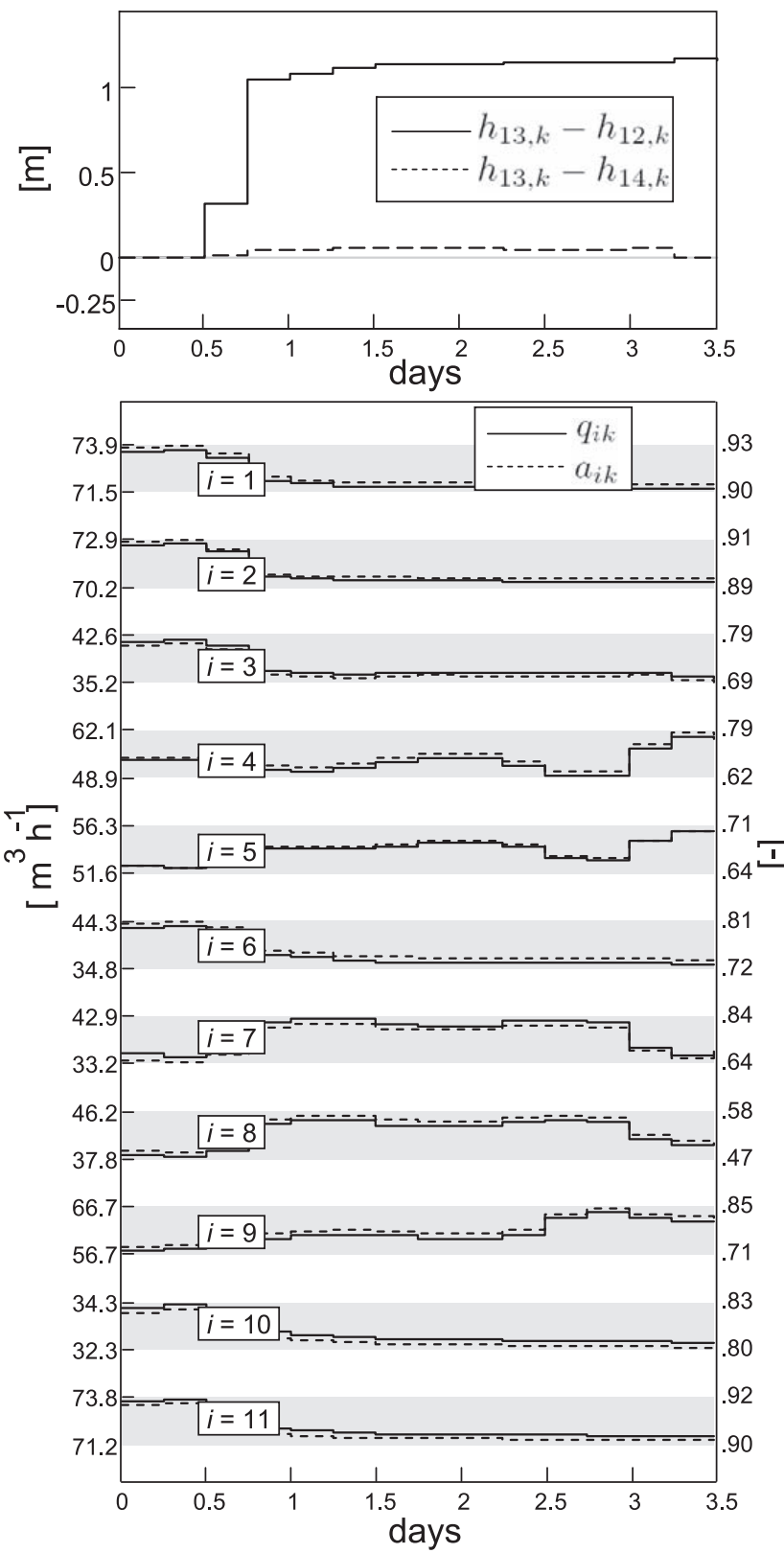
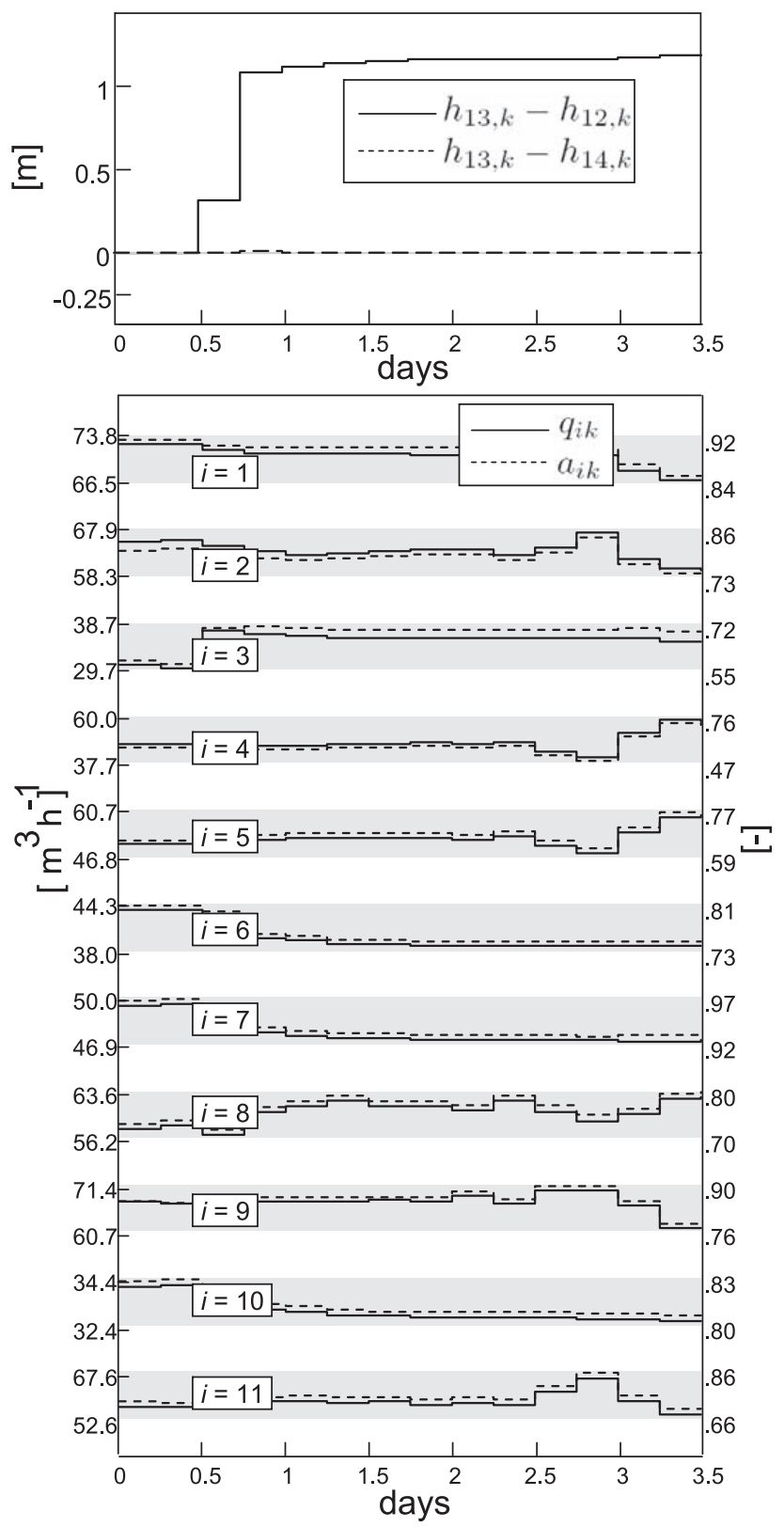

Figure 8. Optimized management solutions when the water demand $d$ is equal to $0.16 \mathrm{~m}^{3} \mathrm{~s}^{-1}$. The left chart shows the solution obtained accounting for the effect of the WDN. The right chart shows the solution obtained neglecting the WDN.

concave, normally they are almost concave. So even when the problem is not convex, it is almost convex, and suboptimal solutions and bounds on their deviation from the optimal solution can be obtained, again by using IP methods.

[46] The optimal management is performed according to the OPTIWELL framework, consisting of three phases: preprocessing, optimization and scheduling. The methodology is tested on the real case study of Søndersø, in Denmark. Results show that even when sufficient conditions for the convexity of the problem are not met, suboptimal solutions can still be obtained with an energy consumption less than $\epsilon=0.01 \%$ off of the of the optimal solution. The advantage of considering the WDN within the management problem of an aquifer system, was also assessed. The presence of the WDN causes a significant overhead (up to $25 \%$ ) in energy consumption.

[47] It was also shown that even if the difference between taking and not taking into account the WDN in optimization may results in a slight increase of energy consumption $(<$ $1 \%$ ), the time pattern of the optimal pumping stresses may be a significantly different. More importantly, the main drawback of not taking the WDN into account in optimization, is that the optimized stresses may be not feasible for the WDN, as the management constraints may be violated.

[48] The IP method used, the barrier method, required a number of Newton step iterations which turned out to be 

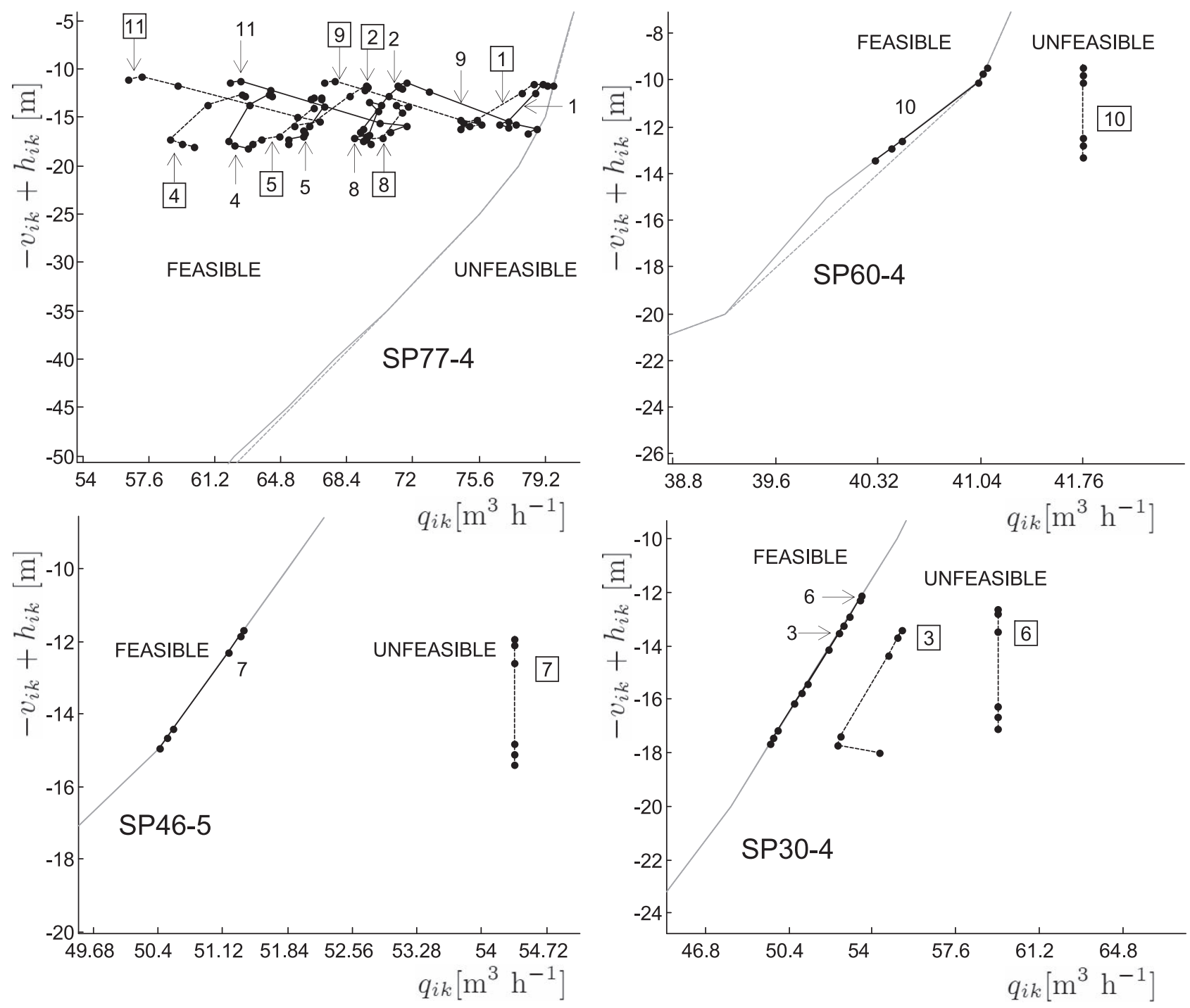

Figure 9. Network constraint fulfillment of optimized management solutions for a problem with $K=6$ decision time steps, water demand $d=0.18 \mathrm{~m}^{3} \mathrm{~s}^{-1}$. Numbers refer to well ids; trajectories labeled with framed numbers are obtained without considering the WDN in the optimization.

weakly dependent on the number of decision variables and constraints. Clearly this is expected not to be true for problems with larger number of wells, time steps and constraints; but it also suggests high capability of IP methods to deal with large-scale problems. The resulting computing time was then mainly influenced by the time taken to compute the objective function, the constraints functions and their first and second-order derivatives.

Table 3. Number of N Steps and Time $F$ for Computing the Objective Functions, Constraint Functions, and All Their First- and Second-Order Derivatives ${ }^{\mathrm{a}}$

\begin{tabular}{ccccccc}
\hline & & \multicolumn{3}{c}{ N Steps } \\
\cline { 3 - 5 }$K$ & Decision Variables & Constraints & $d=.08$ & $d=.12$ & $d=.18$ & Evaluation Time $F[\mathrm{~s}]$ \\
\hline 6 & 66 & 84 & 74 & 77 & 72 & 0.0205 \\
10 & 110 & 140 & 80 & 79 & 78 & 0.0362 \\
15 & 165 & 210 & 72 & 88 & 73 & 0.0746 \\
20 & 220 & 364 & 78 & 101 & 74 & 0.1324 \\
26 & 286 & 434 & 68 & 81 & 63 & 0.2007 \\
31 & 341 & & & & \\
\hline
\end{tabular}

${ }^{\mathrm{a}}$ Water demand $d$ is in $\mathrm{m}^{3} \mathrm{~s}^{-1}$. 


\section{Appendix A: Derivations}

[49] In what follows symbols $\mathbb{A}, \mathbb{B}, \ldots$ denote matrices. We show that the Hessian of both $V_{i}$ and $\mathcal{P}$ are referable to a particular type of matrix, constructed as follows

$$
\mathbb{M}=\sum_{r=1}^{N} z_{r} \mathbb{O}_{r},
$$

where $z_{r}$ are nonnegative scalars and the $i, j$ element of matrix $\mathbb{O}_{r}$ is

$$
\mathbb{O}_{i j r}= \begin{cases}1 & i \geq r \quad \text { or } \quad j \geq r \\ 0 & \text { otherwise }\end{cases}
$$

for example, for $N=4$,

$$
O_{3}=\left[\begin{array}{llll}
0 & 0 & 1 & 1 \\
0 & 0 & 1 & 1 \\
1 & 1 & 1 & 1 \\
1 & 1 & 1 & 1
\end{array}\right] .
$$

We refer to a matrix like $\mathbb{M}$ as a 'matrix of type $\mathrm{O}$ '. These matrices are diagonal and their elements $O_{i j r}$ are non decreasing as $i$ and/or $j$ increase:

$$
\mathbb{O}_{i, j, k}=\sum_{r=1}^{\min \{i, j\}} z_{r}
$$

The $\mathrm{O}$ matrices are positive definite, as for any vector $\mathbf{x} \in \mathfrak{R}^{N}$, the quadratic form $\mathbf{x}^{\top} \mathbb{M} \mathbf{x}$ is always positive, i.e.,

$$
\mathbf{x}^{\top} \mathbb{M} \mathbf{x}=z_{1}\left(\sum_{i=1}^{N} x_{i}\right)^{2}+z_{2}\left(\sum_{i=2}^{N} x_{i}\right)^{2}+\cdots+z_{N} x_{N}^{2} \geq 0 .
$$

[50] The total energy consumption $\mathcal{P}=\sum_{k=1}^{K} \sum_{i=1}^{N} p_{i k}$, is function of the stresses $\mathbf{q}_{1}, \ldots, \mathbf{q}_{K}$. Since the aquifer is confined, then $h_{i k}=\sum_{j=1}^{N} \sum_{k^{\prime}=1}^{k} q_{j k^{\prime}} \theta_{i j, k-k^{\prime}+1}+b_{i k}$, and the Hessian can be put in the form of a $K$-by- $K$ lower triangular block matrix, whose $k$ th diagonal block $B_{k, k}$ is a $N \times N$ matrix, whose $i, j$ element is

$$
\begin{aligned}
& B_{i j k k}=\frac{\partial^{2} \mathcal{P}}{\partial q_{i k} \partial q_{j k}}= \\
& =\frac{1}{\eta_{j}} \frac{\partial v_{j k}}{\partial q_{i k}}+\frac{1}{\eta_{i}} \frac{\partial v_{i k}}{\partial q_{j k}}-\frac{\alpha}{\eta_{j}} \frac{\partial h_{j k}}{\partial q_{i k}}+\sum_{r=1}^{N} \frac{q_{r k}}{\eta_{r}} \frac{\partial^{2} v_{r}}{\partial q_{i k} \partial q_{j k}}
\end{aligned}
$$

where $\alpha$ is equal to 2 is $i=j$ and 1 otherwise. The total energy consumption $\mathcal{P}$ is a convex function of the stresses if $\mathbb{B}_{k, k}$ is positive definite, for all $k=1, \ldots, K$. Since equation $\mathrm{A} 4$ is independent of $k$, all blocks are the same, so we refer to them using $\mathbb{B}$ instead of $\mathbb{B}_{k}$. Without loss of generality, each branch of an unlooped WDN can be considered as $N$ wells connected in series, so we have that

$$
\begin{aligned}
& V_{i}(\mathbf{q})=f_{i, i-1}\left(q_{i}+q_{i+1}+\cdots+q_{N}\right)+ \\
& +f_{i-1, i-2}\left(q_{i-1}+\cdots+q_{N}\right)+\cdots+\quad f_{1,0}\left(q_{1}+\cdots+q_{N}\right)+v_{0} .
\end{aligned}
$$

Based on equation (A5), we derive the first-order partial derivative

$$
\frac{\partial v_{j}}{\partial q_{i}}=\frac{\partial v_{i}}{\partial q_{j}}=\sum_{r=1}^{\min \{i, j\}} \frac{d f_{r, r-1}}{d w_{r, r-1}},
$$

and then we derive the second-order partial derivative

$$
\frac{\partial^{2} v_{r}}{\partial q_{i} \partial q_{j}}=\sum_{r^{\prime}=1}^{\min \{i, j, r\}} \frac{d^{2} f_{r^{\prime}, r^{\prime}-1}}{d w_{r^{\prime}, r^{\prime}-1}^{2}} .
$$

As discussed in section 3, functions $f_{i j}$ are convex and monotonic, hence $d f_{i j} / d w_{i j} \geq 0$, and $d^{2} f_{i j} / d w_{i j}^{2} \geq 0$. Based on this and on equations (A3), (A7), follows that the Hessian $\partial^{2} V_{r} / \partial \mathbf{q}^{2}$ is a $\mathrm{O}$ matrix, hence positive definite for all $r=1, \ldots, N$, thus proving point (1). By combining equations (A5), (A6), and (A7) into equation (A4), the elements $B_{i j}$ take the form

$$
\begin{aligned}
& B_{i j}=\frac{\partial^{2} P}{\partial q_{i} \partial q_{j}}=\frac{\eta_{i}+\eta_{j}}{\eta_{j} \eta_{i}} \sum_{r=1}^{\min \{i, j\}} \frac{d f_{r, r-1}}{d w_{r, r-1}}+\cdots \\
& \cdots-\frac{\alpha}{\eta_{j}} \frac{\partial h_{j}}{\partial q_{i}}+\sum_{r=1}^{N} \sum_{r^{\prime}=1}^{\min \{i, j, r\}} \frac{d^{2} f_{r^{\prime}, r^{\prime}-1}}{d w_{r^{\prime}, r^{\prime}-1}^{2}} \sum_{r^{\prime \prime}=r^{\prime}}^{N} \frac{q_{r^{\prime \prime}}}{r_{r^{\prime \prime}}}
\end{aligned}
$$

hence, matrix $\mathbb{B}$ is the sum of three matrices

$$
\mathbb{B}=\mathbb{V}-\mathbb{H}+\mathbb{W},
$$

which are positive definite, as $-\mathbb{H}$ has the same properties as the Jacobian matrix $-\partial \mathbf{h}_{k} / \partial \mathbf{q}_{k}$, and matrices $\mathbb{V}$ and $\mathbb{W}$ are $\mathrm{O}$ matrices (equation (A3)). This proves point (2), as the sum of positive definite matrices is again positive definite.

[51] Acknowledgments. This work was funded by the Danish Strategic Research Council, Sustainable Energy and Environment Programme, as part of the Well Field optimization project (see http://wellfield. dhigroup.com/).

\section{References}

Ahlfeld, D., and G. Baro-Montes (2008), Solving unconfined groundwater flow management problems with successive linear programming, $J$. Water Resour. Plann. Manage., 134(5), 404-412, doi:10.1061/ (ASCE)0733-9496134:5(404):2008.

Ahlfeld, D., and M. Heidari (1994), Applications of optimal hydraulic control to ground-water systems, J. Water Resour. Plann. Manage., 120(3), 350-365, doi:10.1061/(ASCE)0733-9496120:3(350):1994.

Ahlfeld, D., and A. Mulligan (2000), Optimal Management of Flow in Groundwater Systems, Academic Press, San Diego, Calif.

Angel, P., J. Hernandez, and R. Agudelo (1999), Fuzzy expert system model for the operation of an urban water supply system, in Computing and Control for the Water Industry, edited by D. Savic and G. A. Walters, pp. 449-457, Res. Stud., Baldock, U.K.

Bear, J. (1979), Hydraulics of Groundwater, McGraw Hill, New York.

Ben-Tal, A., and A. Nemirovski (2001), Lectures on Modern Convex Optimization. Analysis, Algorithms, and Engineering Applications, Soc. for Indust. and Appl. Math., Philadelphia, Pa.

Bot, R. I., Grad, S.-M., and G. Wanka (2007), Almost convex functions: Conjugacy and duality, in Generalized Convexity and Related Topics, Lecture Notes Econ., Vol. 583, edited by A. M. Rubinov, pp. 101-114, Springer, New York.

Boyd, S., and L. Vandenberghe (2004), Convex Optimization, Cambridge Univ. Press, New York. 
Burnell, D., J. Race, and P. Evans (1993), An overview of the trunk scheduling system for the london ring main, in 6th IAWO Workshop on Instrumentation, Control and Automation of Water and Wastewater Treatment and Transport Systems, Hamilton, Canada, Water Sci. Technol., Vol. 28, pp. 99-109, IWA, London.

Chase, D., and L. Ormsbee (1993), Computer-generated pumping schedules for satisfying operational objectives, J. Am. Water Works Assoc., 85(7), 54-61.

Fowler, K., et al. (2008), Comparison of derivative-free optimization methods for groundwater supply and hydraulic capture community problems, $A d v$. Water Resour., 31(5), 743-757, doi:10.1016/j.advwatres.2008.01.010.

Gorelick, S. (1983), Review of distributed parameter groundwater management modeling methods, Water Resour. Res., 19(2), 305-319.

Graham, D., and M. Butts (2006), Flexible, Integrated Watershed Modelling with MIKE SHE, edited by D. Graham and M. Butts, pp. 245-272, CRC Press, Boca Raton, Fla.

Halford, K., and R. Hanson (2002), User guide for the drawdown-limited, multi-node well (MNW) package for the U.S. Geological Survey modular three-dimensional finite-difference ground-water flow model, Versions MODFLOW-96 and MODFLOW-2000, U.S. Geol. Surv. Tech. Rep., 02-293.

He, L., G. Huang, and H. Lu (2008), A simulation-based fuzzy chanceconstrained programming model for optimal groundwater remediation under uncertainty, Adv. Water Resour., 31(12), 1622-1635, doi:10.1016/ j.advwatres.2008.07.009,.

Heidari, M. (1982), Application of linear system theory and linear programming to groundwater management in Kansas, Water Resour. Bull., 18(6), 1003-1012.

Jowitt, P., and G. Germanopoulos (1992), Optimal pump scheduling in water-supply networks, J. Water Resour. Plann. Manage., 118(4), 406422, doi:10.1061/(ASCE)0733-9496118:4(406):1992.

Kalwij, I., and R. Peralta (2008), Non-adaptive and adaptive hybrid approaches for enhancing water quality management, J. Hydrol., 358(34), 182-192, doi:10.1016/j.jhydrol.2008.05.036.

Kansal, M., G. Arora, C. León, S. Martín, J. Elena, and J. Luque (2001), Explore-Hybrid expert system for water networks management, $J$. Water Resour. Plann. Manage., 127(6), 415-416, doi:10.1061/(ASCE) 0733-9496(2001)127:6(415).

Katsifarakis, K., and Z. Petala (2006), Combining genetic algorithms and boundary elements to optimize coastal aquifers' management, J. Hydrol., 327(1-2), 200-207, doi:10.1016/j.jhydrol.2005.11.016.

Katsifarakis, K., D. Karpouzos, and N. Theodossiou (1999), Combined use of bem and genetic algorithms in groundwater flow and mass transport problems, Eng. Anal. Bound. Elem., 23(7), 555-565.

Kürstein, J., J. A. Andersen, and J. Mahrt (2009), Sjællandsmodellen - et integreret modelværktøj for det hydrologiske vandkredsløb, Tech. rep., Miljøministeriet, Roskilde og Niras, Denmark.

Lansey, K., and K. Awumah (1994), Optimal pump operations considering pump switches, J. Water Resour. Plann. Manage., 120(1), 17-35, doi:10.1061/(ASCE)0733-9496120:1(17):1994.

Likeman, M. (1993), Constraint satisfaction methods in water supply scheduling, in Integrated Computer Applications in Water Supply, edited by B. Coulbeck, pp. 213-225, Res. Stud., Taunton, U.K.

Maddock, T. (1972), Algebraic technological function from a simulation model, Water Resour. Res., 8(1),129-134.

Mantoglou, A., M. Papantoniou, and P. Giannoulopoulos (2004), Management of coastal aquifers based on nonlinear optimization and evolutionary algorithms, J. Hydrol., 297(1-4), 209-228, doi:10.1016/j.jhydrol.2004.04.011.

Matott, L., A. Rabideau, and J. Craig (2006), Pump-and-treat optimization using analytic element method flow models, Adv. Water Resour., 29(5), 760-775, doi:10.1016/j.advwatres.2005.07.009.

Mayer, A., C. Kelley, and C. Miller (2002), Optimal design for problems involving flow and transport phenomena in saturated subsurface systems, Adv. Water Resour., 25(8-12), 1233-1256, doi:10.1016/S0309-1708(02) 00054-4.

Mays, L. W. (1997), Optimal Control of Hydrosystems, Marcel Dekker, New York.
Mays, L. W., and Y.-K. Tung (1992), Hydrosystems Engineering and Management, McGraw-Hill, New York.

McKinney, D., and M. Lin (1994), Genetic algorithm solution of groundwater-management models, Water Resour. Res., 30(6), 1897-1906.

McKinney, D., and M. Lin (1995), Approximate mixed-integer nonlinearprogramming methods for optimal aquifer remediation design, Water Resour. Res., 31(3), 731-740.

Minciardi, R., M. Robba, and R. Sacile (2007), Decision models for sustainable groundwater planning and control, Control Eng. Practice, 15(8), 1013-1029, doi:10.1016/j.conengprac.2006.10.017.

Nitivattananon, V., E. Sadowski, and R. Quimpo (1996), Optimization of water supply system operation, J. Water Resour. Plann. Manage., 122(5), 374-384, doi:10.1061/(ASCE)0733-9496(1996)122:5(374).

Ormsbee, L., and S. Reddy (1995), Nonlinear heuristic for pump operations, J. Water Resour. Plann. Manage., 121(4), 302-309, doi:10.1061/ (ASCE)0733-9496121:4(302):1995.

Ormsbee, L., T. Walski, D. Chase, and W. Sharp (1989), Methodology for improving pump operation efficiency, J. Water Resour. Plann. Manage., 115(2), 148-164, doi:10.1061/(ASCE)0733-9496(1989)115:2(148).

Ouazar, D., and H. D. Cheng (2000), Application of genetic algorithms in water resources, in Groundwater Pollution Control, edited by K. Katsifarakis, pp. 293-316, WIT Press, Southampton, U.K.

Papadopoulou, M., G. Pinder, and G. Karatzas (2007), Flexible timevarying optimization methodology for the solution of groundwater management problems, Eur. J. Oper. Res., 180(2), 770-785, doi:10.1016/ j.ejor.2006.02.041

Park, C.-H., and M. Aral (2004), Multi-objective optimization of pumping rates and well placement in coastal aquifers, J. Hydrol., 290(1-2), 80-99, doi: 10.1016/j.jhydrol.2003.11.025.

Rastogi, A. (1989), Optimal pumping policy and groundwater balance for the blue lake aquifer, california, involving nonlinear groundwater hydraulics, J. Hydrol., 111(1-4), 177-194, doi:10.1016/0022-1694(89)90259-X.

Rossman, L. (2000), Epanet 2 users manual, technical report, Risk Reduct. Eng. Lab., U.S. Environ. Protect. Agency, Cincinnati, Ohio.

Shieh, H., and R. Peralta (2005), Optimal in situ bioremediation design by hybrid genetic algorithm-simulated annealing, J. Water Resour. Plann. Manage., 131(1), 67-78, doi:10.1061/(ASCE)0733-9496131:1(67):2005.

Sidiropoulos, E., and P. Tolikas (2004), Well locations and constraint handling in pumping cost minimization via genetic algorithms, Water Air Soil Pollut., 4(4-5), 227-239.

Simpson, A., and S. Elhay (2011), Jacobian matrix for solving water distribution system equations with the darcy-weisbach head-loss model, $J$. Hydraul. Eng., 137(6), 696-700.

Spiliotopoulos, A., G. Karatzas, and G. Pinder (2004), A multiperiod approach to the solution of groundwater management problems using an outer approximation method, Eur. J. Oper. Res., 157(2), 514-525, doi: 10.1016/S0377-2217(03)00239-X.

Theodossiou, N. (2004), Application of non-linear simulation and optimisation models in groundwater aquifer management, Water Resour. Manage., 18(2), 125-141.

Tsai, F.-C., V. Katiyar, and R. Goff (2009), Conjunctive management of large-scale pressurized water distribution and groundwater systems in semi-arid area with parallel genetic algorithm, Water Resour. Manage., 23(8), 1497-1517.

van Zyl, J., D. Savic, and G. Walters (2004), Operational optimization of water distribution systems using a hybrid genetic algorithm, J. Water Resour. Plann. Manage., 130(2), 160-170, doi:10.1061/(ASCE)07339496(2004)130:2(160).

Wagner, B. J. (1995), Recent advances in simulation-optimization groundwater management modeling, U.S. Natl. Rep. Int. Union Geod. Geophys. 1991-1994, Rev. Geophys., 33, 1021-1028.

Yeh, W.-G. (1992), Systems analysis in ground-water planning and management, J. Water Resour. Plann. Manage., 118(3), 224-237, doi:10.1061/ (ASCE)0733-9496118:3(224):1992.

Yu, G., R. Powell, and M. Sterling (1994), Optimized pump scheduling in water distribution systems, J. Optim. Theory Appl., 83(3), 463-488. 